\title{
TEORIAS DEMOCRÁTICAS DE DIREITO: O PROCEDIMENTALISMO VERSUS O SUBSTANCIALISMO E A INTERVENÇÃO DO PODER JUDICIÁRIO NAS POLÍTICAS PÚBLICAS
}

Francieli Puntel Raminelli* Cristiane Penning Pauli de Menezes**

\section{RESUMO}

O Estado Democrático de Direito se diferencia por intentar a real modificação do status quo. Para que seja assegurado este objetivo, duas são as teorias que se confrontam: a Procedimentalista e a Substancialista. Assim, questiona-se: qual deve ser a postura adotada pelo Poder Judiciário? O objetivo deste trabalho é analisar a decisão de um Tribunal brasileiro quanto à intervenção do Judiciário nas políticas públicas da Administração, por meio da matriz teórica fenomenológico-hermenêutica. Como método de procedimento, utiliza-se o monográfico. Conclui-se que a alternativa de um Judiciário ativo e balizado por uma interpretação hermeneuta da Constituição é a solução.

PALAVRAS-CHAVE: Procedimentalismo; Substancialismo; Direitos Sociais-Fundamentais;

\section{DEMOCRATIC THEORY OF LAW: PROCEDURALISM VERSUS SUBSTANTIALISM AND INTERVENTION OF THE JUDICIARY IN PUBLIC POLICY}

\begin{abstract}
The Democratic Rule of Law differs by attempting to actually change the status quo. In order to achieve this objective, two theories are confronted: Proceduralist and Substantialist. Thus, one wonders: what should be the position adopted by the Judiciary? The objective of this work is to analyze the decision of a Brazilian Court regarding the intervention of the Judiciary in the public policies of the Administration, through the theoretical phenomenological-hermeneutical matrix. As method of procedure, the monographic is used. We conclude that the alternative of an active judiciary and marked by a hermeneutic interpretation of the Constitution is the solution.
\end{abstract}

KEY WORDS: Proceduralism; Substantialism; Fundamental Social Rights.

\footnotetext{
* Mestra em Direito pela Universidade Federal de Santa Maria. Doutoranda em Direito pelo Programa de PósGraduação da Universidade Federal do Rio Grande do Sul, com bolsa CAPES, e membro dos grupos de pesquisa Direitos Fundamentais e Novos Direitos e Sociologia Judiciária, ambos inscritos na plataforma dos grupos de pesquisa do CNPq, sob orientação do Prof. Dr. José Alcebíades de Oliveira Junior. E-mail: francieli.raminelli@gmail.com.

** Mestra em Direito pela Universidade Federal de Santa Maria. Coordenadora do Núcleo de Estudos em Direito Internacional (NEDI) da Faculdade de Direito de Santa Maria (FADISMA). Professora de Direito da Faculdade de Direito de Santa Maria (FADISMA). Doutoranda no Programa de Pós-graduação em Processos e Manifestações Culturais - Universidade Feevale. E-mail: cristianepaulidemenezes@gmail.com.
}

Revista de Teorias da Justiça, da Decisão e da Argumentação Jurídica | e-ISSN: 2525-9644 | Salvador | v. 4 | n. 1 | p. 1 - 21 | 


\section{INTRODUÇÃO}

A construção do atual Estado Democrático de Direito transpassa uma evolução histórica da formação do Estado Moderno. Se inicialmente o Poder Soberano do Rei no Estado Absolutista imperou, cerceando direitos e liberdades, não tardou para a derrocada deste sistema opressor, com um novo, que possuía liberdade no nome, assumindo seu lugar. Por óbvio o sistema Liberal não representou a solução dos problemas das camadas mais pobres da sociedade, que permaneceram à margem do crescimento burguês, mas, sem sombra de dúvidas, a subordinação de todo o sistema à lei representou uma grande modificação na estrutura social.

Felizmente também o sistema Liberal, devido as suas características mais intrínsecas de um capitalismo exacerbado e de um juiz "boca-da-lei”, cedeu lugar a um Estado com objetivos sociais, no qual a igualdade era levantada como objetivo precípuo. Com o consentimento da burguesia, que também já sofria efeitos colaterais devido as grandes tensões sociais, surge o Estado do Bem Estar Social, voltado à construção de uma sociedade, se não mais igualitária, ao menos em condições de prover os direitos mais básicos do cidadão.

Entretanto, os fins do Estado Social também não foram alcançados, sendo necessária a reformulação do sistema social para que a igualdade fosse efetivamente atingida. Esta efetiva mudança no status quo do direito é o plus do Estado Democrático de Direito, que consigo traz a promessa de concretização dos direitos sociais-fundamentais, básicos e essenciais a uma vida digna.

Com a evolução deste Estado, conjuntamente ocorreu a evolução do Direito, que se adequou e modificou de acordo com as novas conquistas da sociedade. Passando pelos diversos tipos de juízes, do que está restrito à lei ao que tem “superpoderes” de decisão, o juiz do Estado Democrático deve estar ligado às normas postas. Entretanto, isto quer dizer que ele se restringe, novamente, a letra da lei, quando esta for democraticamente construída? Ou se trata de uma nova maneira de permitir a interpretação da norma posta, uma interpretação hermenêutica constitucional que permite a resposta correta e adequada aos problemas enfrentados neste novo paradigma?

Neste sentido, para responder a esta questão, que é objeto de inúmeras discussões em âmbito acadêmico e social devido à importância do papel do juiz no contexto moderno, objetiva-se analisar as duas teorias principais acerca da construção de uma justiça adequada ao Estado Democrático de Direito: a Teoria Procedimentalista e a Teoria Substancialista. Em especial, após esta compreensão teórica, intenta-se abordar uma decisão oriunda dos Tribunais

Revista de Teorias da Justiça, da Decisão e da Argumentação Jurídica | e-ISSN: 2525-9644 | Salvador | v. 4 | n. 1 | p. 1 - 21 | 


\section{TEORIAS DEMOCRÁTICAS DE DIREITO: O PROCEDIMENTALISMO VERSUS O SUBSTANCIALISMO E A INTERVENÇÃO DO PODER JUDICIÁRIO NAS POLÍTICAS \\ PÚBLICAS}

Brasileiros acerca da (im)possibilidade de intervenção judicial em políticas públicas, questão cerne no embate entre estas duas teorias.

Por este motivo, a pesquisa adota um caráter ("método" de abordagem) fenomenológico-hermenêutico. Diz-se fenomenológico porque se centra na descrição dos próprios fatos observados, e por possibilitar uma compreensão advinda da volta ao mundo da vida, a partir da qual o sujeito se reconhece como protagonista deste mundo. E, hermenêutica, pois parte da tese de que a experiência vivida é em si mesma essencialmente um processo interpretativo, no qual a realidade é compreendida, interpretada e comunicada. Como "método" de procedimento, utiliza-se o monográfico, uma vez que será realizado o estudo de um caso específico oriundo da jurisprudência do Estado Brasileiro. Por fim, como técnicas de pesquisa, opta-se pela pesquisa documental e bibliográfica.

Ainda, o presente artigo esta dividido em três partes, a saber: (1) Estado democrático de direito: concepção histórica de seu desvelar até a Modernidade; (2) Procedimentalismo x Substancialismo: duas teorias, um objetivo; e (3) O Estado Brasileiro e as decisões intervencionistas do judiciário nas políticas públicas: procedimentalista, substancialista ou solipsista?.

\section{Estado Democrático de Direito: concepção histórica de seu desvelar até a modernidade}

A Constituição Federal Brasileira aduz, em seu artigo primeiro, que a República Federativa do Brasil constitui-se em Estado Democrático de Direito (BRASIL, 1988). Este fato, além de ser uma “norma” expressa na Constituição, entretanto, possui um fundo histórico e um significado muito mais amplo do que apenas definir um modelo estatal no país, principalmente no que diz respeito aos anseios da sociedade e à aplicação do direito.

Compreender o contexto em que o Brasil se insere requer uma retomada histórica da construção do Estado Moderno, que se inicia com o chamado Estado Absolutista². Caracterizado pelos excessos do clero e da nobreza, e considerado "um aparelho de dominação feudal, alargado e reforçado” (SOARES, 2008, p.79), este modelo estatal propiciou a unidade

\footnotetext{
${ }^{2}$ De acordo com Nicola Matteucci, o Estado Absoluto se caracteriza pela tendência do monopólio do poder político e da força por parte de uma instância superior que não reconhece outra autoridade nem no plano internacional, nem no plano interno, já que não admite em seu seio nenhuma justiça privada nem instância que possa participar do poder político (MATTEUCCI, 1998, p. 29, livre tradução).
}

Revista de Teorias da Justiça, da Decisão e da Argumentação Jurídica | e-ISSN: 2525-9644 | Salvador | v. 4 | n. 1 | p. 1 - 21 | 
jurídica e o poder de Estado no continente europeu, além de transformar o Estado em uma forte entidade capitalista. Através da política mercantilista, "fomentou o advento de um poder burguês muito potente, configurado no capital móvel financeiro, comercial e industrial” (SOARES, 2008, p.79).

Com o fortalecimento da burguesia, o terceiro Estado iniciou a reivindicação por votos por cabeça, e não por Estado. No modelo utilizado, os dois primeiros Estados, o clero e a nobreza, os quais representavam cerca de 200 mil privilegiados franceses, possuíam dois votos, e o terceiro estado, composto por mais de 25 milhões de pessoas, somente um (STRECK e MORAIS, 2006, p. 48). Neste contexto de conflitos e dificuldades para sua solução, eclodiram inúmeras revoltas, as quais culminaram na principal delas, a Revolução Francesa. Após este importante fato histórico, o qual retirou terminantemente o poder das mãos dos reis absolutistas, a burguesia inaugurou seu poder político como classe (STRECK e MORAIS, 2006, p. 49) e originou a emergência do Estado Liberal de Direito.

Sendo o Estado Liberal um estado burguês, possuía o fim precípuo de “dar aqueles que controlavam a economia (os burgueses) ampla liberdade de exercerem suas atividades, sem estarem ameaçados por qualquer outro poder” (ARAUJO, 1997). Sua base fundamental estava construída sobre a Teoria da Separação dos Poderes, ou Teoria Tripartida, que, devido a pluralidade de poderes, enfraquece a monarquia (ou o poder único).

A grande característica do Estado Liberal era o fato de que o Estado estava restrito ao Direito e à Lei, que restringia as ações do governante, em um sentido de proteção de liberdade individuais, mas também os poderes do Juiz que, devido ao alicerce da jurisdição liberal em uma dogmática normativo-positivista acrítica, não poderia interpretar a lei (norma), mas somente aplicá-la na busca por verdades absolutas (LUCAS, 2005, p. 179-180) ${ }^{3}$. Desta forma, este Estado caracteriza-se por ser mínimo, respeitando os direitos individuais e não intervindo na economia, a qual era considerada auto regulável. O Estado Liberal de Direito, assim, não se restringe somente ao respeito à norma, no sentido estrito da legalidade, mas emerge aliado ao conteúdo próprio do Liberalismo ${ }^{4}$.

Como consequência disto, constroem-se as demais características do Estado Liberal: a separação entre Estado e Sociedade Civil, a garantia das liberdades individuais, a democracia

\footnotetext{
${ }^{3}$ Esta vinculação do Juiz a palavra do legislador é apontada como uma das causas da aproximação do Processo Civil e o Direito às ciências exatas e de demonstração, afastando-se das ciências da compreensão, visto que ao juiz não era permitido interpretar (ISAIA, 2012, p. 112).

${ }^{4}$ Para Bobbio, o liberalismo é uma concepção do Estado, na qual este possui poderes e funções limitados, ao contrário do Estado Absoluto e do atual Estado Social (BOBBIO, 1994, p.7).
}

Revista de Teorias da Justiça, da Decisão e da Argumentação Jurídica | e-ISSN: 2525-9644 | Salvador | v. 4 | n. 1 | p. 1 - 21 | 


\section{TEORIAS DEMOCRÁTICAS DE DIREITO: O PROCEDIMENTALISMO VERSUS O SUBSTANCIALISMO E A INTERVENÇÃO DO PODER JUDICIÁRIO NAS POLÍTICAS \\ PÚBLICAS}

vinculada ao ideário da soberania e o Estado com um papel reduzido (STRECK e MORAIS, 2006, p.95), além, é claro, do Juiz “boca da lei” ou “Juiz Júpiter”5 (OST, 1993, p. 170).

Em vista disto, o Liberalismo mostrou-se como uma "teoria anti estado" (STRECK e MORAIS, 2006, p. 56), no qual a intervenção do Estado além dos limites “aceitáveis” é prejudicial, porquanto enfraquece a independência característica do mercado capitalista. Assim, neste modelo, o crescimento da atuação do Estado é diretamente responsável pela diminuição dos espaços das liberdades individuais, objeto de proteção Liberal.

Entretanto, a supervalorização das atividades econômicas sem o controle Estatal propiciou uma sociedade desigual, assimétrica (ARAUJO, 1997, p. 25). Com ela, surge uma postura ultra individualista, uma concepção individualista e formal da liberdade, na qual há a liberdade e não o poder de ser livre; igualmente, forma-se o proletariado, em consequência da Revolução Industrial (STRECK e MORAIS, 2006, p. 62). Por estas consequências, o conceito limitador do Estado de garantidor da paz e da segurança é modificado, assumindo também outros papéis, como o de prestador de serviços públicos, ou, até mesmo como interventor socioeconômico (STRECK e MORAIS, 2006, p. 58). O Estado passa a intervir em espaços até então próprios da iniciativa privada desaparecendo, assim, a figura do Estado Mínimo.

Outrossim, apesar da intervenção aparentemente ser contrária aos interesses burgueses, os quais eram beneficiados pelo sistema liberal, os resultados da intervenção estatal foram positivos para os eles, em vários aspectos. Podem ser citados, por exemplo, a amenização das tensões sociais existentes, as quais representavam ameaças, a oferta infraestrutura para o desenvolvimento das atividades comerciais através do financiamento público, ou seja, a divisão dos custos do desenvolvimento por todos e a oportunidade de benefícios decorrentes da concessão de obras e serviços públicos (STRECK e MORAIS, 2006, p. 69). Desta forma, com a concordância da burguesia, beneficiada igualmente por este novo modelo, nasce o Estado do Bem-Estar social (ou Welfare State), com escopos interventivos e promocionais. O Estado Social de Direito apresenta-se como "um tipo de Estado que tende a criar uma situação de bemestar geral que garanta o desenvolvimento da pessoa humana” (STRECK e MORAIS, 2006, p. 91).

\footnotetext{
${ }^{5}$ Para Ost, o Juiz Júpiter é aquele que profere decisões desde cima, como se de um "Monte Sinai”, sendo que o direito adota a forma de lei e deste "foco supremo de juridicidade" emana o resto do Direito em forma de decisões particulares (OST, 1993, p. 170).
}

Revista de Teorias da Justiça, da Decisão e da Argumentação Jurídica | e-ISSN: 2525-9644 | Salvador | v. 4 | n. 1 | p. 1 - 21 | 
Diferentes dos antigos modelos de Estados assistencialistas, o Estado do Bem-Estar Social oferece as prestações públicas como um direito do cidadão, conquistados através da cidadania. São garantidos tipos mínimos de renda, alimentação, saúde, habitação, educação e outros direitos denominados de "sociais", sendo estes direitos políticos e não caridade (STRECK e MORAIS, 2006, p. 71). Além disso, o Estado Social de Direito utiliza a lei não mais somente como norma geral e abstrata, mas como norma específica e com destinação concreta. Assim, a transformação do Estado Liberal para Social se dá igualmente na reconceitualização de seu mecanismo básico de ação: a lei.

Contudo, apesar do conteúdo social agregado ao Estado, ainda não existe a concretização da igualdade, somente percebida de modo formal, não materialmente. Isto talvez se justifique porque o Estado, apesar de representar uma superação do Liberal, mantém-se fiel à ordem capitalista (ISAIA, 2012, p. 145). Neste período, a história é marcada por conflitos extremados, como aquele entre a classe detentora de capital e a classe trabalhadora das fábricas (ARAUJO, 1997, p. 27), motivo pelo qual o Estado intenta compreender a sociedade em sua realidade social.

Com isto, “o exercício da função jurisdicional assume nova roupagem” (ISAIA, 2012, p.148), tendo que lidar com todos os novos direitos sociais, oriundos deste contexto capitalista e conflituoso. Assim, o juiz no Estado Social torna-se um “ator ativista”, assumindo o papel ativo na aproximação entre Estado e Sociedade e fazendo uso de uma “justiça distributiva”. Isto porque o Estado Social “distribuiu bens jurídicos de conteúdo material, disponibilizando a sociedade uma série de mecanismos institucionais (e processuais) adequados para protegê-la” (ISAIA, 2012, p. 150).

Entretanto, com a grande quantidade de promessas que não conseguiram ser cumpridas pelo Estado, as esperanças do povo se voltaram ao Poder Judiciário. Por este motivo, ao juiz “são conferidos” poderes de interferir em tarefas e atividades de outras instituições, sendo denominado de Juiz Hércules, aquele que "se submete a trabalhos esgotadores de julgar e acaba a levar o mundo sobre seus braços estendidos” (OST, 1993, p. 170, livre tradução).

Este trabalho hercúleo assumido pelo juiz, entretanto, gera o problema de que a atividade jurisdicional ultrapassa o controle na promoção e efetivação das políticas públicas sociais, sendo que ao juiz foi concedido o “poder criativo”, que “se justificaria pelo aumento do poder discricionário dos juízes oriundo da tentativa de implementação das políticas públicopromocionais” (ISAIA, 2012, p. 153) do Estado Social. 


\section{TEORIAS DEMOCRÁTICAS DE DIREITO: O PROCEDIMENTALISMO VERSUS O SUBSTANCIALISMO E A INTERVENÇ̃̃O DO PODER JUDICIÁRIO NAS POLÍTICAS PÚBLICAS}

Nesse sentido, ao invés de romper com o paradigma da concepção sujeitoindividualista oriunda do Estado Liberal, o direito permaneceu detido em um rito voltado a resoluções de questões individuais, vinculado ao prosseguimento de procedimentos ordinários e à subjetividade do julgador, solipsista ${ }^{6}$, preso no movimento racional-iluminista e à filosofia da consciência ${ }^{7}$ (ISAIA, 2012, p. 158).

Tendo em vista as dificuldades do Estado Social de garantir a almejada igualdade material, pretende-se agregar valores verdadeiramente democráticos ao Estado de Direito, conjugando o ideal democrático. Neste “conjunto”, agregam-se as conquistas democráticas, as garantias jurídico-legais e a preocupação social. É deste novo conceito que se oriunda o Estado Democrático de Direito, o qual possui como escopo principal a transformação do status quo, com um conteúdo transformador da realidade, não se restringindo a melhorias nas condições dos cidadãos.

Conforme Lenio Luiz Streck e José Luis Bolzan de Morais (2006, p. 97), o Estado Democrático de Direito possui um conteúdo transformador da realidade, diferente do Estado Social, que objetivava uma adaptação melhorada das condições sociais de existência. Nesse sentido, seu conteúdo não apenas se restringe ao aspecto material de concretização da vida digna ao ser humano; pelo contrário, simbolicamente, é um fomentador da participação pública no processo de construção e reconstrução de um projeto de sociedade, uma vez que se apropria “do caráter incerto da democracia para veicular uma perspectiva de futuro voltada à produção de uma nova sociedade, onde a questão da democracia contém e implica, necessariamente, a solução do problema das condições materiais da existência” (STRECK; MORAIS, 2006, p. 97).

Assim, o Estado Democrático de Direito possui o objetivo de transformar a realidade não somente no aspecto de melhorar as condições de vida do cidadão, tido apenas como um “objeto” nas mãos do Estado, mas também de propiciar a este indivíduo condições de opinar para a construção ou, se preciso, desconstrução da sociedade, até que esta esteja de acordo com

\footnotetext{
${ }^{6}$ O Solipsismo é "a crença de que, além de nós, só existem as nossas experiências. É a consequência extrema de se acreditar que o conhecimento deve estar fundado em estados de experiências interiores e pessoais, e de não se conseguir encontrar uma ponte pela qual esses estados nos deem a conhecer alguma coisa que esteja além deles. O solipsismo do momento presente estende este ceticismo aos nossos próprios estados passados, de tal modo que tudo o que resta é o eu presente" (BLACKBURN, 1997, p. 367).

${ }^{7}$ A filosofia da consciência, em brevíssima explicação, refere-se ao paradigma da subjetividade, que surgiu na modernidade e é, basicamente, o esquema sujeito-objeto, em que o mundo é explicado e fundamentado pela razão. Neste sistema, o sujeito "muda de posição" em relação ao iluminismo, uma vez que passa a "assujeitar" as coisas. A fase posterior, oriunda do giro linguístico, ao contrário, tende a ver o ser humano com um sujeito no mundo, uma vez que ele é um ente que compreende a si mesmo (STRECK, 2013, p. 13-15).
}

Revista de Teorias da Justiça, da Decisão e da Argumentação Jurídica | e-ISSN: 2525-9644 | Salvador | v. 4 | n. 1 | p. 1 - 21 | 
suas as expectativas e necessidades. Em outras palavras, busca a democracia voltada ao futuro, para a construção de uma nova sociedade, englobando a solução dos problemas de cunho material, e não somente regulamentando-os. É necessário que exista uma real modificação nas condições dadas às classes mais baixas, sendo que o Direito é a ferramenta para que isto ocorra.

Neste sentido, para Canotilho (1993, p. 43, grifos do autor), o Estado Democrático de Direito é balizado "por uma lei fundamental escrita (= constituição juridicamente constitutiva das "estruturas básicas da justiça") e pressupõe um modelo de legitimação tendencialmente reconduzível à legitimação democrática”. Ou seja, o modelo deste estado impõe necessariamente a existência de uma lei base, uma constituição, a qual estará ligada a democracia, uma vez que irá balizar e definir direitos e deveres, conforme a vontade popular, sendo, por este motivo, legitimamente democrática. Além disso, sugere a superação de um Estado de Direito, uma vez que intenta efetivar os direitos sociais, e, desta forma, a justiça social, “condição de possibilidade na correção de desigualdades” (ISAIA, 2012, p. 161).

Desta forma, o artigo primeiro da Constituição Federal Brasileira, que destaca o Brasil como Estado Democrático de Direito, é o resultado histórico da união de componentes de outros conceitos de Estados de Direito, como as liberdades individuais, políticas e econômicas do Estado Liberal, o escopo do bem-estar social, do Estado Social e a igualdade, do Estado Democrático. Tem o Estado Democrático de Direito Brasileiro o principal objetivo da “realização do indivíduo numa sociedade não só livre, mas justa e solidária” (ARAUJO, 1997, p. 39). Outrossim, o Estado é visto como instrumento de transformação, inserindo um teor social de garantias das condições mínimas de vida digna à igualdade formal, no qual "a questão da democracia contém e implica, necessariamente, a solução do problema das condições materiais de existência” (STRECK e MORAIS, 2006, p. 98).

Tem-se, portanto, que o escopo do Estado Democrático de Direito é transformar a sociedade, atendendo suas expectativas frustradas com os modelos anteriores e concretizando direitos sociais sem, com isto, ignorar os direitos individuais típicos do modelo Liberal de Estado. Neste contexto, o papel jurisdicional mais uma vez modifica-se, já que recebeu "tanto a função de zelar quanto a de implementar, a partir dos textos constitucionais, os direitos sociais” (ISAIA, 2012, p. 162).

Isto indica que ao Poder Judiciário cabe a tarefa de interferir, ainda que muitas vezes acabe por desrespeitar a máxima liberal de separação dos poderes, sem que com essa atitude, ressalte-se, seja retomado o modelo de juiz semideus Hércules, detentores de todos os poderes 


\section{TEORIAS DEMOCRÁTICAS DE DIREITO: O PROCEDIMENTALISMO VERSUS O SUBSTANCIALISMO E A INTERVENÇÃO DO PODER JUDICIÁRIO NAS POLÍTICAS PÚBLICAS}

e filiado à Teoria da Consciência e à subjetividade. Justamente por isto, o papel do Poder Judiciário no Estado Democrático é questão cerne discutida entre duas teorias que contemplam esta perspectiva democrática, que buscam evitar discricionariedades e subjetividades. Abordar estas teorias e os diferentes caminhos que elas apresentam para a superação deste problema é o objetivo do próximo capítulo.

\section{Procedimentalismo X Substancialismo: duas teorias, um objetivo}

O Estado Democrático de Direito é a etapa final da construção de um modelo democrático que respeite os direitos fundamentais do cidadão, ao mesmo tempo em que constrói uma possiblidade de efetiva mudança do status quo, ao efetivar estes direitos ${ }^{8}$. Neste contexto, existe uma grande discussão acerca do papel do Judiciário na busca deste objetivo, de forma que seja superado o paradigma da Filosofia da Consciência, na qual o juiz "decide conforme sua consciência”, embasado na razão, na subjetividade e em um sistema sujeito-objeto (STRECK, 2013, p. 100-120).

Entretanto, para a garantia de um Estado Democrático em que a Constituição tenha um papel relevante e destacado, sendo superado o modelo liberal imposto ${ }^{9}$ e sem que existam discricionariedades e arbitrariedades, foram construídas duas teorias, a fim de superar o modelo da filosofia da consciência que ainda hoje prevalece: a Teoria Procedimentalista e a Teoria Substancialista.

Estas teorias, apesar do objetivo comum de garantir a democracia e evitar uma “jurisprudência de valores” ${ }^{10}$, possuem uma maneira distinta de visualizar a inserção da

\footnotetext{
${ }^{8}$ Para o Professor Lenio Streck, a indissociável ligação entre o Estado Democrático de Direito e a realização dos direitos fundamentais é o que pode se denominar de "plus normativo" deste Estado (STRECK, 2007, p. 39).

${ }^{9}$ É necessário que um novo modelo, que considere os direitos sociais seja construído, desvinculando-se do direito posto no Estado Liberal, voltado apenas para a satisfação de classes burguesas e vinculado estritamente à lei. Nesse sentido, "Este modus de ser jurídico (dos juristas) necessita de posições de rompimento com a pós-modernidade, possibilitando o acontecer de um novo jeito de ver - de perceber - o Direito, ou seja, a capacidade de percebê-lo enquanto existencial, enquanto condição de existência para o social” (ISAIA; HOFFMAM, 2012, P. 168).

10 A Jurisprudência de Valores pode ser compreendida como um ponto de equilíbrio entre a Jurisprudência dos Conceitos e a Jurisprudência dos Interesses. A primeira diz respeito, em suma, ao objetivo de atingir-se um direito como um sistema pleno, hermeticamente fechado, devido ao contexto social de caráter científico. Neste ponto, o direito está diretamente ligado ao método. Já a segunda busca encontrar soluções para os "problemas da vida", em uma visão utilitarista, sendo que deseja encontrar o direito exigido pela vida. Ao juiz e ao legislador era possível uma atividade parcialmente cognitiva e parcialmente valorativa, apesar da vinculação formal ainda existir. Por fim, quanto a Jurisprudência de Valores, em si, trata-se da formação de conceitos gerais que consigam apreender sozinhos o maior número possível de fenômenos mediante a descrição de poucas características comuns a todos
}

Revista de Teorias da Justiça, da Decisão e da Argumentação Jurídica | e-ISSN: 2525-9644 | Salvador | v. 4 | n. 1 | p. 1 - 21 | 
Constituição junto ao Estado, e, por isto, se confrontam com frequência, também em razão dos diferentes caminhos que apontam para o alcance de um modelo ideal. Por este motivo, é essencial enfrentá-las em suas fundamentações teóricas, a seguir.

A Teoria Procedimentalista tem como principal doutrinador o alemão Jünger Habermas, que critica com veemência a invasão da política e da sociedade pelo Direito (HABERMAS, 2003, p. 297a) e pretende, por meio da teoria do Discurso (Teoria do Agir Comunicativo), ultrapassar os modelos dos dois Estado anteriores ao Democrático de Direito. Para Habermas, a função central neste Estado cabe à legislação política (STRECK, 2007, p. 41).

Com isto, Habermas pretende substituir a razão prática, existente na filosofia da consciência, por sua teoria do agir comunicativo, que é dividida em duas partes: os discursos de fundamentação e os discursos de aplicação.

Os discursos de fundamentação habermasianos compõem-se basicamente de práticas argumentativas sob as quais os seus participantes discutem a respeito de temas socialmente relevantes com vistas ao entendimento recíproco - pretensão de validade universal. Os entendimentos resultantes destes discursos são chamados de consenso ou verdade (HABERMAS, 2003, p. 250-251a).

A Fundamentação ou justificação discursiva dispõe, portanto, que o destinatário de uma norma deve ver nela seu intuito individual coletivizado, institucionalizado por procedimentos previamente conhecidos. A devida fundamentação, que é realizada em condições de fala ideal, sem efeitos da linguagem sobre o intérprete ou a sociedade, resulta na aceitabilidade por todos os atores, sendo que Habermas busca distinguir seu discurso de fundamentação de qualquer filosofia ligada à consciência e dar aplicabilidade prática a seu procedimento discursivo (HABERMAS, 2003, p. 250-270a). Todos os discursos de fundamentação devem ser realizados no "grau zero", que viabiliza a "fala ideal”, sendo que a ética era acrescida apenas depois da realização desta fase (STRECK, 2012, p. 94).

Quanto aos discursos de aplicação, consistem no momento em que as normas fundamentadas pelos cidadãos, ou consenso, serão aplicadas, devendo seguir uma interpretação de acordo com o pretendido no momento em que foram criadas. Em outras palavras, e trazendo a comparação para o Estado, os discursos de aplicação seriam a "jurisdição", ou seja, a

eles, ou seja, tendo o ideal de justiça como valor absoluto, o direito é concebido através de uma finalidade essencial colocada fora de si mesmo (BARRETO, 2006, p. 482-492).

Revista de Teorias da Justiça, da Decisão e da Argumentação Jurídica | e-ISSN: 2525-9644 | Salvador | v. 4 | n. 1 | p. 1 - 21 | 


\section{TEORIAS DEMOCRÁTICAS DE DIREITO: O PROCEDIMENTALISMO VERSUS O SUBSTANCIALISMO E A INTERVENÇÃO DO PODER JUDICIÁRIO NAS POLÍTICAS PÚBLICAS}

interpretação direta da fundamentação já existente (legislação). Com isto, é possível que se realize uma separação visível entre poderes, uma vez que ao juiz caberia apenas encontrar a correspondência entre fatos e normas, sem necessidade de fundamento - que já foram realizados previamente. De acordo com Habermas,

Somente o legislador político tem o poder ilimitado de lançar mão de argumentos normativos e pragmáticos, inclusive os constituídos através de negociações equitativas, isso porém, no quadro de um procedimento democrático amarrado à perspectiva da fundamentação de normas. A justiça não pode dispor arbitrariamente dos argumentos enfeixados nas normas legais; os mesmos argumentos, porém, desempenham um papel diferente quando são aplicados num discurso jurídico de aplicação que se apoia em decisões consistentes e na visão da coerência do sistema jurídico em seu todo (HABERMAS, 2003, p. 239a).

Nesse sentido, e fazendo críticas à leitura substancialista de Alexy do modelo construtivo do Direito de Dworkin, Habermas critica o "gigantismo do Judiciário", além da "Leitura Moral” da Constituição (Dworkin), a hermenêutica jurídica, o realismo jurídico e o positivismo jurídico (HABERMAS, 2003, p. 245-254a). Afirma que não foi solucionada a questão acerca da forma como uma interpretação construtiva do Direito poderia ser realizada, tendo em vista a Separação dos Poderes dos Estados, uma vez que não seria possível que o um poder subjugasse o outro, sendo que "a lógica da divisão dos poderes não pode ser ferida pela prática de um Tribunal que não possui meios de coerção para impor suas decisões contra uma recusa do parlamento e do governo" (STRECK, 2007, p. 42).

No mesmo sentido, Habermas critica a ideia da concretização de valores materiais constitucionais, uma vez que se conduzindo por esta ideia, “o Tribunal Constitucional transforma-se numa instancia autoritária” (HABERMAS, 2003, p. 321a). Além disso, prossegue explicando que quando um Tribunal "adota a doutrina de valores e toma como base sua própria prática de decisão, cresce o perigo dos juízos irracionais, porque, neste caso, os argumentos funcionalistas prevalecem sobre os normativos” (HABERMAS, 2003, p. 322a).

Com isto, a proposta que realiza é a de um modelo de democracia constitucional que se fundamenta em procedimentos que asseguram a formação democrática da opinião e da vontade, em um contexto de uma “nação de cidadãos” e não de cultura (STRECK, 2007, p. 43). Isto vai ao encontro de sua repelência a jurisprudência de valores de Tribunais Europeus, principalmente o Alemão, o que opta por uma interpretação de normas e princípios em seu sentido teleológico e ignora o caráter vinculante do sistema de direitos constitucionalmente assegurados.

Revista de Teorias da Justiça, da Decisão e da Argumentação Jurídica | e-ISSN: 2525-9644 | Salvador | v. 4 | n. 1 | p. 1 - 21 | 
Assim, quando se trata do papel dos Tribunais Constitucionais, Habermas defende que a esses cabe apenas a tarefas de zelar pela criação democrática do direito, ficando limitados à função de compreensão procedimental da Constituição (HABERMAS, 2003, p. 170b). Indiscutivelmente, este é o ponto central de divergência entre o procedimentalismo e o substancialismo.

A tese substancialista compreende que o papel do Poder Judiciário está além de apenas harmonizar e equilibrar os Poderes. A ele também caberia a função de ser um intérprete que “põe em evidência, inclusive contra as maiorias eventuais, a vontade geral implícita no direito positivo, especialmente nos textos constitucionais, e nos princípios selecionados como de valor permanente na sua cultura de origem e na do Ocidente” (STRECK, 2007, p. 45). Sendo assim, o modelo proposto pelas Teorias Materiais da Constituição (ou substancialista), com base no fundamento de que a Constituição é a “explicitação do contrato social”, entende que ela estabelece as condições do “agir político-estatal”, tratando-se do constitucionalismo dirigente, inserido nas constituições após a segunda guerra mundial (STRECK, 2007, p. 46).

Atribuindo à Constituição este papel de extrema relevância, justifica-se que ao Poder Judiciário também seja designada importância, mormente pela positivação dos direitos sociaisfundamentais. Isto porque diante do contexto de modificação social do Estado, que busca a alteração da igualdade apenas formal, o Judiciário não pode se manter inerte perante a sociedade. Cabe a ele assumir uma postura ativa, buscando a interpretação e implementação da vontade implícita dos textos constitucionais, uma vez que o Estado Democrático de Direito está fundado em uma "democracia contemporânea que, a partir de uma atuação judicial transformadora da realidade, é calcada no prisma substancial, através de uma postura promocional-prestacional” (ISAIA, 2012, p. 163).

De acordo com o Professor Lenio Streck, causídico da Teoria Substancialista no Brasil, um dos doutrinadores que mais se destaca na defesa do substancialismo é o norte-americano Laurence Tribe (STRECK, 2007, p. 46). Entre outras, Tribe critica com elevada acidez a visão procedimentalista da Constituição, que a compreende apenas garantir acesso aos mecanismos de participação democrática no sistema (TRIBE apud STRECK, 2007, p. 46). Além dele, outros teóricos apresentam inúmeras objeções a teoria dos valores adjetivos (ou procedimentalista), como, por exemplo, Luigi Ferrajoli (que prega uma democracia constitucional, na qual a Constituição alcança uma posição de garantia da divisão dos poderes e dos direitos fundamentais e a sujeição ao Direito de todos os Poderes, incluindo o Legislativo), o português 


\section{TEORIAS DEMOCRÁTICAS DE DIREITO: O PROCEDIMENTALISMO VERSUS O SUBSTANCIALISMO E A INTERVENÇÃO DO PODER JUDICIÁRIO NAS POLÍTICAS PÚBLICAS}

Jorge Miranda, os brasileiros Paulo Bonavides, Dalmo Dallari, Ingo Sarlet, Eros Grau, entre outros (STRECK, 2007, p. 46-49).

Em síntese, as teorias substancialistas de forma geral compreendem que o Poder Judiciário deve assumir uma postura intervencionista, agindo ativamente para que as promessas não cumpridas da modernidade, principalmente quanto aos direitos sociais-fundamentais. Não compreendem esta intervenção como um enfraquecimento da democracia, pelo contrário, a apresentam como uma efetiva solução ao problema, uma vez que para alcançar “[...] um grau de legitimidade democrática das decisões é necessário o enfrentamento deste problema em todas as dimensões e não uma saída pessimista, que procura resolvê-lo a partir da construção de uma estrutura que não aniquila o solipsismo do sujeito, mas apenas o ignora” (STRECK, 2012, p. 208). Esta é, ademais, uma das principais críticas realizadas ao procedimentalismo, uma vez que Habermas realiza a substituição da razão prática pela razão comunicativa, o que não "fere de morte" a teoria da consciência, apenas a desloca da razão prática à razão comunicativa (STRECK, 2012, p. 93-102). Ademais, diante da Teoria Procedimentalista, temse que a Constituição possui um papel voltado apenas a uma forma de defesa do cidadão contra privações abusivas de sua liberdade, e não para corrigir omissões estatais na defesa de direitos fundamentais. Assim, no procedimentalismo não há como corrigir escolhas flagrantemente equivocadas feitas pelo Legislador ou pelo Poder Executivo (STRECK, 2012, p. 186).

Para o professor Lênio Streck (2012, p. 179), a solução (substancialista) é a utilização da resposta correta, ou seja, a resposta adequada à Constituição ${ }^{11}$. E esta apenas poderá ser alcançada quando seu parâmetro for a situação concreta, no qual serão analisados os fatos e realizada a interpretação consoante a Constituição.

Neste ponto, é imperioso ressaltar que a teoria substancialista não se confunde com o ativismo judicial ou decisionismos por parte de juízes e Tribunais. Desta forma, “defender um certo grau de dirigismo constitucional e um nível determinado de exigência de intervenção da justiça constitucional não pode significar que os tribunais se assenhorem da Constituição” (STRECK, 2012, p. 192). De mesma maneira, a teoria de Habermas não aceita discricionariedades, também apostando na possibilidade de se obter apenas uma resposta

\footnotetext{
${ }^{11}$ Neste sentido é importante referir que jamais será possível que o Legislador preveja e regule todas as situações da vida em sociedade, tanto pela velocidade como novos direitos são "construídos" quanto pelo distanciamento entre os legisladores e os cidadãos das atuais democracias. Ademais, ao contrário do que a maioria deseja e prega, o direito material e processual não estão e nunca estiveram separados, o que refuta a falácia chiovendiana de que o juiz está pobremente limitado à tarefa de “declarar” (SALDANHA, 2011, p. 360).
}

Revista de Teorias da Justiça, da Decisão e da Argumentação Jurídica | e-ISSN: 2525-9644 | Salvador | v. 4 | n. 1 | p. 1 - 21 | 
correta, exatamente da mesma forma que a teoria hermenêutica aponta (STRECK, 2012, p. 101).

No Brasil, entretanto, apesar das discussões intermináveis entre as duas teorias, a adoção de nenhuma das duas teses é “perceptível”. Por este motivo, o próximo tópico objetiva analisar uma decisão judicial de intervenção do Poder Judiciário em políticas públicas, especificamente quanto ao direito social-fundamental à educação.

\section{O Estado Brasileiro e as decisões intervencionistas do judiciário nas políticas públicas: procedimentalista, substancialista ou solipsista?}

De acordo com o Professor Lenio Streck, nenhuma das Teorias Procedimentalista ou Substancialista estão explicitamente demonstradas no plano do agir cotidiano dos juristas no Brasil. Nesse sentido, se o Estado Brasileiro está distante de uma postura substancialista, tendo em vista a inefetividade da maioria dos direitos sociais e da posição do Judiciário frente a mandados de injunção e ações diretas de inconstitucionalidades por omissão (que são remédios utilizados de forma insatisfatória), também não possui uma prática procedimentalista de acordo com a proposta por Habermas (STRECK, 2007, p. 50-51).

Isto porque as rotineiras submissões do Congresso e as utilizações indiscriminadas de medidas provisórias por parte do Executivo ferem o núcleo do paradigma procedimentalista do direito, "pois a combinação universal e a mediação recíproca entre a soberania do povo institucionalizada juridicamente e a não-institucionalizada são a chave para se entender a gênese democrática do direito” (HABERMAS, 2003, p. 186 - a). Significa dizer, “a visão democrática de direitos e da garantia da preservação dos procedimentos legislativos aptos a estabelecer a autonomia dos cidadãos” (STRECK, 2007, p. 51) está distante do que ocorre no Brasil, principalmente pela subordinação do Legislativo (função que se igualaria aos discursos da fala ideal de fundamentação) aos outros Poderes.

Nesse sentido, a atuação do Poder Judiciário de acordo com cada teoria é diversa, sendo que, se no procedimentalismo ele é visto apenas como aplicador das leis já criadas (discurso de aplicação), no substancialismo ele assume um papel mais ativo, a fim de concretizar a previsão constitucional e agir balizado por ela (buscando a única resposta correta e adequada). Entretanto, em ambas existe um cuidado com a limitação do exercício deste poder, já que “não se pode confundir [...] a adequada/necessária intervenção da jurisdição

Revista de Teorias da Justiça, da Decisão e da Argumentação Jurídica | e-ISSN: 2525-9644 | Salvador | v. 4 | n. 1 | p. 1 - 21 | 


\section{TEORIAS DEMOCRÁTICAS DE DIREITO: O PROCEDIMENTALISMO VERSUS O SUBSTANCIALISMO E A INTERVENÇÃO DO PODER JUDICIÁRIO NAS POLÍTICAS PÚBLICAS}

constitucional com a possibilidade de decisionismos por parte de juízes e tribunais” o que "seria antidemocrático” (STRECK, 2012, p. 192).

Na análise dos casos concretos do Judiciário Brasileiro, entretanto, muitas vezes são encontrados casos em que, ultrapassando o limite constitucional imposto para o encontro da resposta adequada, os juízes decidem de acordo com usa própria consciência. Esta questão normalmente aparece inserida e justificada sob o "manto do poder discricionário” dos juízes (STRECK, 2013, p. 20), e acarreta em decisões fundamentadas das mais diversas formas, ainda que Streck (2012, p. 192) ressalte que a interpretação do texto não significa que o intérprete possa "dizer qualquer coisa sobre qualquer coisa, atribuindo sentidos de forma arbitrária aos textos”.

Inúmeras são as decisões que aplicam, entretanto, a interpretação pessoal do juiz acerca do tema discutido, ignorando qualquer uma das teorias abordadas e aplicando a discricionariedade baseada no solipsismo judicial. Por este motivo, optou-se pela análise de um caso oriundo do Poder Judiciário Brasileiro no qual, a margem de qualquer fundamentação, a “Justiça” de primeiro grau adotou uma postura intervencionista na política pública de educação do Governo do Mato Grosso do Sul.

O caso em questão envolve uma Ação Civil Pública proposta pelo Ministério Público do Mato Grosso do Sul em face deste mesmo Estado, requerendo na Justiça que este fosse condenado a realizar reformas no prédio da Escola Estadual Professora Vânia Medeiros Lopes, localizada no Município de Glória de Dourados/MS, devido a existência de várias irregularidades que exigiam a adequação das instalações físicas da referida escola.

Em primeiro grau a ação foi julgada procedente, sendo o Estado condenado a realizar inúmeras modificações, entre elas fornecer material esportivo, reformar de salas de aula de modo genérico, adaptar do espaço para inclusão de salas destinadas a laboratórios, construir refeitórios, adaptar da sinalização de trânsito no entorno da escola, planejar e construir um local adequado para acondicionamento do lixo, entre outras (BRASIL, 2010).

Entretanto, após apelação interposta pelo Estado, o Tribunal de Justiça do Mato Grosso do Sul deu provimento ao pedido do Apelante, tendo em vista que o direito social-fundamental à educação estava sendo cumprido (BRASIL, 2010). Isto porque não cabe ao Poder Judiciário, em consonância com o artigo $2^{\circ}$ da Constituição Federal, que determina os três poderes (Executivo, Legislativo e Judiciário) harmônicos e independentes entre si (BRASIL, 1988),

Revista de Teorias da Justiça, da Decisão e da Argumentação Jurídica | e-ISSN: 2525-9644 | Salvador | v. 4 | n. 1 | p. 1 - 21 | 
obrigar o Chefe do Poder Executivo a realizar políticas públicas determinando, no caso, que a escola Vânia Medeiro Lopes deveria recebê-las em detrimento de outras escolas que também necessitariam (BRASIL, 2010).

Inicialmente, poderia se pensar que a sentença se trata de uma adoção da Teoria Substancialista, que prega a necessidade de um Poder Judiciário ativo junto às necessidades da população, para o alcance dos direitos sociais-fundamentais. De fato, é uma característica desta teoria a defesa de que, em países de modernidade tardia como o Brasil, que não passaram pela fase do Estado Social, diante da inércia dos Poderes Executivo e Legislativo, possa o Poder Judiciário intervir com a Justiça Constitucional na busca da concretização dos direitos fundamentais de várias dimensões (STRECK, 2012, p. 191). Entretanto, utilizar-se deste objetivo de concretização dos direitos não significa que o Poder Judiciário deve controlar a forma como estes devem ser realizados.

Por direitos sociais-fundamentais entendem-se como sendo "prestações positivas proporcionadas pelo Estado direta ou indiretamente, enunciadas em normas constitucionais, que possibilitam melhores condições de vida aos mais fracos” (SILVA, 2008, p. 183). Entre estes direitos se inserem o direito à saúde, à alimentação, ao trabalho, à moradia, ao lazer, à segurança, à previdência social, à proteção à maternidade e à infância, à assistência aos desamparados, e, é claro, à educação (BRASIL, 1988).

Devido a esta amplitude de “dimensões” destes direitos, a discussão no âmbito do Judiciário acerca da efetividade e cumprimento por parte do Estado é muito numerosa. No âmbito da saúde, por exemplo, a busca por medicamentos, cirurgias e outros procedimentos relativos à cura de enfermidades junto ao Judiciário é extremamente alto. Por óbvio este direito relaciona-se a outros, como o direito à vida, além de basear-se no fundamento constitucional de proteção da Dignidade da Pessoa Humana (BRASIL, 1988).

No pertinente à educação, entretanto, tendo em vista que não pode ser assegurado apenas em situações pontuais, mas em políticas de desenvolvimento e em continuidade, o número de demandas individuais que versam sobre seu acesso é reduzido, sendo normalmente propostas ações de natureza coletiva, como é o caso. Pela Constituição, mormente em seu artigo 205 e seguintes (BRASIL, 1988), estão protegidos o direito à educação básica e fundamental, sendo garantidas as condições de segurança mínimas para sua realização.

É necessário ressaltar, no entanto, que a caracterização do acesso à educação não se confunde com as condições físicas do ambiente escolar, ao contrário do que postulou o 


\section{TEORIAS DEMOCRÁTICAS DE DIREITO: O PROCEDIMENTALISMO VERSUS O SUBSTANCIALISMO E A INTERVENÇÃO DO PODER JUDICIÁRIO NAS POLÍTICAS PÚBLICAS}

Ministério Público do Estado do Mato Grosso do Sul. Apesar de ser um pedido “justo” e plausível, uma vez que as crianças necessitam de um ambiente saudável e seguro para estudar, no caso em concreto não se comprovou que, devido às necessidades de reforma da escola, o direito à educação não estava sendo exercido.

De acordo com os autos, a escola estava em pleno funcionamento, não restando demonstrado que houvesse uma proteção insuficiente e não estando os alunos impedidos de estudar, sendo que a estrutura do prédio não comprometia de modo grave o direito à educação (BRASIL, 2010).

Ademais, a interpretação com o princípio da divisão dos poderes, imposto pela própria constituição, conduz à premissa de que não é dado ao Poder Judiciário impor ao Chefe do Executivo Estadual a obrigação de reformar o prédio de uma Escola Estadual. Isto porque ao Poder Judiciário incumbe o controle judicial sobre atos administrativos do Poder Executivo, porém a sua competência se restringe ao controle da legalidade e da legitimidade, o que não corresponde ao caso em questão. Ordenar a concretização de uma obra na escola, neste caso, seria adentrar no mérito administrativo, ou seja, na conveniência, oportunidade, eficiência ou justiça do ato administrativo.

Nesta esteira, a decisão que deu provimento à apelação do Estado pontua que a execução da obra pretendida pelo Ministério Público, qual seja, a reforma nas instalações físicas da escola, não depende apenas da vontade do Chefe do Executivo (BRASIL, 2010). Aponta que “os obstáculos são os mais variados, sendo que o principal deles é de conhecimento público, a falta de recursos financeiros” sendo que o "Estado de Mato Grosso do Sul possui várias escolas espalhadas em todos seus municípios que também necessitam de manutenção” (BRASIL, 2010).

Apesar de este argumento ter algum fundamento no questionável argumento da "Reserva do Possível"12, utilizada pelo Estado frequentemente quando são requeridos direitos sociais-fundamentais, a questão transpassa o que se caracteriza por direito à educação,

\footnotetext{
${ }^{12}$ O princípio da reserva do possível origina-se da chamada cláusula da reserva do possível, utilizada pela primeira vez em um julgamento promovido pelo Tribunal Constitucional alemão, em decisão conhecida como Numerus Clausus (BverfGE n. ${ }^{\circ}$ 33, S. 333). Neste julgamento, a Corte alemã julgou improcedente uma demanda judicial proposta por estudantes não admitidos em escolas de medicina de Hamburgo e Munique em face da política de limitação do número de vagas em cursos superiores, adotada pela Alemanha em 1960. A pretensão dos estudantes foi fundamentada no artigo 12 da Lei Fundamental daquele Estado, segundo a qual "todos os alemães têm direito a escolher livremente sua profissão, local de trabalho e seu centro de formação" (MÂNICA, 2007). Percebe-se que o contexto alemão em muito difere do brasileiro, no qual muitas vezes sequer a educação básica é garantida.
}

Revista de Teorias da Justiça, da Decisão e da Argumentação Jurídica | e-ISSN: 2525-9644 | Salvador | v. 4 | n. 1 | p. 1 - 21 | 
mormente entendido como direito ao acesso ao conhecimento , sendo cerne o questionamento acerca da possibilidade do Poder Judiciário impor como obrigação do Estado Brasileiro fornecer condições impecáveis para este acesso, como é o caso de uma “escola ideal” em questões estruturais.

Por certo, o melhor seria que o Brasil tivesse escolas ideais, hospitais ideais, moradias ideais e todos os direitos garantidos com perfeição. Entretanto, este estágio ainda está longe de ser estabelecido, sendo necessário conhecer a realidade brasileira, na qual muitas vezes sequer direitos básicos são garantidos. Assim, tem-se como questionável e até mesmo discricionária a decisão de primeiro grau do caso em tela, uma vez que cabe ao Poder Executivo, após a implementação dos direitos básicos à educação, melhor administrar seus recursos, aplicandoos nas escolas ou entidades que deles mais necessitam (como citado na própria decisão, no Estado do Mato Grosso do Sul muitas outras escolas encontram-se na mesma ou em pior situação) (BRASIL, 2010).

Analisada as decisões tomadas em primeiro e segundo grau pelo Poder Judiciário quanto à necessidade de sua intervenção nas políticas da Administração Pública, tem-se que neste caso concreto o juiz extrapolou a interpretação da Constituição Federal. Esta garante apenas o direito à educação, sem fazer referência a uma educação em condições utópicas, tendo em vista o patamar em que o Brasil se encontra (ou seja, ainda não atingiu todos os direitos sociais, sendo alguns dos mais básicos ainda ineficientes).

Portanto, a decisão de condenar o Estado a realizar reformas em irregularidades que não impedem a acesso à educação não se enquadraria dentro das teses substancialistas, uma vez que não responde ao problema adequadamente e em consonância com a constituição. Tampouco poderia ser entendida como uma decisão procedimentalista, uma vez que para Habermas o juiz jamais poderia criar novos discursos de fundamentação, apenas deve aplicar os já existentes.

Trata-se, então, de um caso de puro solipsismo judicial, em que o juiz decidiu extrapolando os limites aceitáveis de uma intepretação hermenêutica constitucional, infelizmente prática comum no cotidiano do Judiciário Brasileiro. Por este motivo, talvez seja essencial concordar com o Professor Lênio Streck (2013, p. 118) quando este afirma que “o direito não é aquilo que o judiciário diz que é”; na verdade, o direito deve ser o que a Constituição diz que ele é, sem interpretações que apenas confirmem decisionismos e discricionariedades, nos moldes requeridos pelo Estado Democrático de Direito.

Revista de Teorias da Justiça, da Decisão e da Argumentação Jurídica | e-ISSN: 2525-9644 | Salvador | v. 4 | n. 1 | p. 1 - 21 | 


\section{TEORIAS DEMOCRÁTICAS DE DIREITO: O PROCEDIMENTALISMO VERSUS O SUBSTANCIALISMO E A INTERVENÇÃO DO PODER JUDICIÁRIO NAS POLÍTICAS PÚBLICAS}

\section{CONCLUSÃO}

O Estado Democrático de Direito Brasileiro, longe de atingir os objetivos e as promessas de efetividade dos direitos sociais-fundamentais, ainda hoje está, com dificuldades, evoluindo na concretização de alguns dos direitos mais básicos do ser humano. Como justificativa para este descumprimento, costuma-se apontar para o fato de que o país não passou por todas fases dos outros Estados Modernos, o que, apesar de ser uma realidade, não pode ser um entrave para seu desenvolvimento.

De qualquer forma, a diferença do patamar onde o Estado Brasileiro se encontra, quando comparado a outros Estados, pode ser o motivo pelo qual a Teoria Procedimentalista de Habermas não parece encaixar-se com perfeição em terrae brasilis. Seja pela inexistência da possibilidade de uma fala ideal, ou pela descrença da população em seus legisladores, que parecem se afastar de seus anseios, a ideia de que o Poder Judiciário permaneça inerte perante tantos desvios e omissões dos outros poderes não parece ser a melhor alternativa.

Por outro lado, a Teoria Substancialista, que defende uma interpretação hermenêutica da Constituição, levando em conta a atual conjuntura brasileira e as diretrizes fixadas pelo constituinte, em busca da resposta mais adequada, aparenta trazer uma esperança de modificação neste Estado (quase) Democrático de Direito. Se infelizmente o plus deste Estado ainda não foi atingido, talvez por meio de um Poder Judiciário ativo e militante, que se mantenha limitado pela Constituição, algumas mudanças podem ser realizadas e alguns direitos concretizados.

Entretanto, para a adoção da Teoria Substancialista, alguns pontos essenciais não podem ser olvidados. Reitera-se que a resposta correta deve estar em total acordo com a Constituição, não se admitindo decisionismos ou arbitrariedades de juízos solipsistas que, muitas vezes por decidirem de acordo com a consciência, utilizam-se dos argumentos mais variados para fundamentação. Além disso, questão cerne na utilização de referia teoria consiste na busca da resposta correta diante do caso concreto, não sendo possíveis discussões em âmbito hipotético ou teórico.

Da análise do caso concreto referente à intervenção judicial na política pública acerca da educação, no Estado do Mato Grosso do Sul, tem-se que no Brasil não existe a utilização de 
uma ou outra teoria; pelo contrário, além de não existir uma definição, ainda existem juízos baseados na filosofia da consciência, paradigma que ambas as teorias intentam superar.

Por este motivo, mais do que um confronto entre elas, o imprescindível é combater os antigos paradigmas, oriundos do Estado Liberal, que apenas buscam a satisfação de direitos individuais, sem a compreensão do ambiente e contexto que o cercam. Apenas com a superação destes será possível a efetiva democratização e a concretização de expectativas que o Estado ainda não conseguiu garantir à sociedade, democrática por Direito.

\section{REFERÊNCIAS}

ARAUJO, Luiz Ernani Bonesso de. O Acesso a Terra no Estado Democrático de Direito. Frederico Westphalen: URI, 1997.

BARRETTO, Vicente. Dicionário de Filosofia do Direito. São Leopoldo: Unisinos - Renovar, 2006.

BLACKBURN, Simon. Dicionário Oxford de Filosofia. Rio de Janeiro: Jorge Zahar Editores, 1997.

BOBBIO, Norberto. Liberalismo e Democracia. 5 ed. São Paulo: Brasiliense, 1994.

BRASIL. Constituição da República Federativa do Brasil de 1988. Disponível em: $<$ http://www.planalto.gov.br/ccivil_03/constituicao/constituicao.htm> Acesso em 10 mar. 2018.

BRASIL. Tribunal de Justiça do Mato Grosso do Sul. Acórdão de decisão que deu provimento à apelação do Estado do Mato Grosso do Sul contra decisão que condenava o

Estado a realizar reformas em prédio público. Apelação Civil no 2009.022755-5/0000-00.

Estado do Mato Grosso do Sul e Ministério Público do Estado do Mato Grosso do Sul.

Relator: Exmo. Sr. Des. Luiz Carlos Santini. 09 de março de 2010.

CANOTILHO, José Joaquim Gomes. Direito Constitucional. 6 ed. Coimbra: Almedina, 1993.

HABERMAS, Jurgen. Direito e democracia: entre faticidade e validade. Tradução de Flávio Beno Siebeneichler. Volume I. 2 ed. Rio de Janeiro: Tempo Brasileiro, 2003 - a.

HABERMAS, Jurgen. Direito e democracia: entre faticidade e validade. Tradução de Flávio Beno Siebeneichler. Volume II. 2 ed. Rio de Janeiro: Tempo Brasileiro, 2003 - b.

ISAIA, Cristiano Becker. Processo civil e hermenêutica: a crise do procedimento ordinário e o redesenhar da jurisdição processual civil pela sentença (democrática) liminar de mérito. Curitiba: Juruá, 2012.

ISAIA, Cristiano Becker; HOFFMAN, Fernando. A jurisdição processual civil no Estado Democrático de Direito: verdades universais ou respostas corretas? In: Revista de direito brasileira (Brazilian Jornal of Law). Coordenação de Vladimir Oliveira da Silveira. Ano 2, Vol. 3, dezembro/2012, p. 157-176.

Revista de Teorias da Justiça, da Decisão e da Argumentação Jurídica | e-ISSN: 2525-9644 | Salvador | v. 4 | n. 1 | p. 1 - 21 | 


\section{TEORIAS DEMOCRÁTICAS DE DIREITO: O PROCEDIMENTALISMO VERSUS O SUBSTANCIALISMO E A INTERVENÇÃO DO PODER JUDICIÁRIO NAS POLÍTICAS \\ PÚBLICAS}

LUCAS, Doglas Cesar. A Crise funcional do Estado e o cenário da jurisdição desafiada. In: O Estado e suas crises. Org. José Luis Bolzan de Morais. Porto Alegre: Livraria do Advogado, 2005.

MÂNICA, Fernando Borges. Teoria da Reserva do Possível: Direitos Fundamentais a Prestações e a Intervenção do Poder Judiciário na Implementação de Políticas Públicas. Revista Brasileira de Direito Público, Belo Horizonte, ano 5, n. 18,p. 169-186, jul./set. 2007.

MATTEUCCI, Nicola. Organización del poder y libertad: historia del constitucionalismo moderno. Tradução para o espanhol de Francisco Javier Ansuátegui Roig y Manuel Martínez Neira. Madrid: Ed. Trotta, 1998.

OST, François. Júpiter, Hércules y Hermes: tres modelos de Juez. In: Doxa: Cuardenos de Filosofia del Derecho, $\mathrm{n}^{\mathrm{0}}$ 14, Alicante, 1993. Disponível em: <http://www.cervantesvirtual.com/servlet/SirveObras/01048841455381501310035/cuaderno1 4/doxa14_11.pdf>. Acesso em 15 maio 2013.

SALDANHA, Jânia Maria Lopes. Substancialização e Efetividade no Direito Processual Civil: a Sumariedade Material da Jurisdição. Proposta de Estabilização da Tutela Antecipada em Relação ao Projeto de Novo CPC. Curitiba: Ed. Juruá, 2011.

SILVA, José Afonso da. Comentário Contextual à Constituição. São Paulo: Malheiros, 2008. SOARES, Mário Lúcio Quintão. Teoria do Estado: novos paradigmas em face da globalização. 3 ed. São Paulo: Atlas, 2008.

STRECK, Lenio Luiz. Hermenêutica Jurídica e(m) crise: uma exploração hermenêutica da construção do Direito. 7 ed. Porto Alegre: Livraria do Advogado, 2007.

STRECK, Lenio Luiz. O que é isto - decido conforme minha consciência? 4 ed. Porto Alegre: Livraria do Advogado, 2013.

STRECK, Lenio Luiz. Verdade e Consenso. Constituição, Hermenêutica e Teorias Discursivas. 4 ed. São Paulo: Saraiva, 2012.

STRECK, Lenio Luiz; MORAIS, José Luis Bolzan de. Ciência Politica e Teoria Geral do Estado. 5 ed. Porto Alegre: Livraria do Advogado, 2006.

Revista de Teorias da Justiça, da Decisão e da Argumentação Jurídica | e-ISSN: 2525-9644 | Salvador | v. 4 | n. 1 | p. 1 - 21 | 